\title{
APLIKASI AKUNTANSI PENCATATAN PENGELUARAN KAS PADA PT. JASA TRANSPORTASI YALA GITHA TAMA CIREBON
}

\author{
Meirani Fajrin ${ }^{1}$, Widya Jati Lestari ${ }^{2}$, Ilwan Syafrinal ${ }^{3}$ \\ Universitas Catur Insan Cendekia Cirebon ${ }^{1,2,3}$ \\ Jl. Kesambi No. 202, Telp. 0231-200418 of Universitas Catur Insan Cendekia \\ Email: meirani216@gmail.com¹, widya.jatilestari@cic.ac.id ${ }^{2}$, ilwan.syafrinal@ cic.ac.id ${ }^{3}$
}

\begin{abstract}
ABSTRAK
PT. Jasa Transportasi Yala Githa Tama (International Freight Forwarding) merupakan perusahaan yang bergerak pada jasa transportasi persewaan alat berat yaitu Forklift dan Crane. Perusahaan ini berlokasi di Jalan Bali No. 3 Pelabuhan Cirebon. Dalam kegiatan pencatatan pengeluaran kas masih menemui kendala yaitu pencatatan pengeluaran kas masih diinput manual menggunakan Microsoft Excel, hal ini dapat menimbulkan kesalahan pencatatan pengeluaran kas dan menjadi tidak efektif. Berdasarkan hal tersebut, maka dibuatlah aplikasi pencatatan akuntansi pengeluaran kas. Sistem berbasis komputer ini berfungsi untuk memudahkan perusahaan dalam melakukan pencatatan terkomputerisasi dan lebih efisien dalam kegiatanya. Tahap analisa dan perancangan sistem digambarkan secara manual menggunakan flowchart, kemudian dibuat secara komputerisasi ke dalam diagram aliran data level 0 dan level 1 disertai dengan diagram hubungan antar entitas, dan relasi antar tabel. Setelah tahap ini selesai, tahap selanjutnya adalah percancangan sistem perangkat lunak. Perancangan tersebut menggunakan bahasa pemrograman PHP (Hypertext Prepocessor) dan menggunakan database MySQL (My structured Query Language). Pada aplikasi ini menghasilkan laporan perencanaan kerja, jurnal umum dan laporan pengeluaran kas.
\end{abstract}

Kata kunci: Aplikasi, Pencatatan, Pengeluaran kas.

\section{Abstract}

PT. Yala Githa Tama (International Freight Forwarding) Transportation Services is a company engaged in heavy equipment rental transportation services, namely Forklifts and Cranes. The company is located at Jalan Bali No. 3 Port of Cirebon. In the activity of recording cash disbursements, there are still obstacles, namely recording cash disbursements is still manually inputted using Microsoft Excel, this can lead to errors in recording cash disbursements and become ineffective. Based on this, an application for accounting for cash disbursements was made. This computer-based system functions to make it easier for companies to carry out computerized records and to be more efficient in their activities. The analysis and system design stage is described manually using a flowchart, then computerized into a level 0 and level 1 data flow diagram accompanied by a relationship diagram between entities, and relationships between tables. After this stage is complete, the next stage is designing a software system. The design uses the PHP (Hypertext Prepocessor) programming language and uses the MySQL (My Structured Query Language) database. In this application produces work planning reports, general journals and reports of cash disbursements.

Keywords: Application, Recording, cash disbursements.

Aplikasi Akuntansi Pencatatan Pengeluaran Kas Pada PT. Jasa Transportasi Yala Githa Tama Cirebon (Widya Jati Lestari, Ilwan Syafrinal, Meirani Fajrin) 


\section{Pendahuluan}

Kemajuan teknologi yang semakin pesat saat ini menuntut berbagai kalangan untuk selalu melakukan perubahan. Kebutuhan akan informasi yang dirasa sangat penting bagi kalangan pengusaha, lembaga formal maupun nonformal diharapkan dapat mereka peroleh dengan serba cepat dan tepat. PT. Jasa Transportasi Yala Githa Tama (International Freight Forwarding) selaku anak perusahaan (Holding Company) dan dibawah naungan Yayasan Sosial Bhumyaca (Yasbhum) Group TNI AL, mengemban amanat untuk mendukung upaya peningkatan kesejahteraan keluarga besar TNI AL. didirikan berdasarkan akte Nomor 02 tanggal 04 bulan Agustus Tahun 1964. Sebagai badan usaha yang bergerak di bidang persewaan alat berat.

Pada prinsipnya pengelolaan keuangan sangatlah penting bagi setiap perusahaan begitu pula pada PT. Jasa Transportasi Yala Githa Tama Cirebon. Khususnya penerapan sistem pengeluaran kas, mengingat kas digunakan untuk membiayai biaya operasional perusahaan. . Untuk mengawasi pengeluaran kas, maka diperlukan pengendalian yang baik terhadap kas dan memerlukan prosedur - prosedur yang memadai untuk melindungi pengeluaran kas. Salah satu aktivitas yang ada pada perusahaan PT. Jasa Transportasi Yala Githa Tama Cirebon adalah mengenai pencatatan pengeluaran kas. Pencatatan akuntansi pada PT. Jasa Transportasi Yala Githa Tama Cirebon umumnya sudah sesuai standar akuntansi keuangan akan tetapi pencatatan pengeluaran kas pada PT. Jasa Transportasi Yala Githa Tama Cirebon masih di input manual menggunakan Microsoft Excel, hal ini mengakibatkan pencatatan pengeluaran kas menjadi belum optimal dan tidak efektif. Penggunaan Microsoft excel dalam membuat laporan perbulan sangat tidak efektif dan membutuhkan waktu yang lama, sehingga akan lama pula informasi yang bisa diterima oleh manajemen dan kurang maksimal keputusan yang dibuat oleh manajemen.

Untuk mengurangi permasalahan yang ada pada PT. Jasa Transportasi Yala Githa Tama dalam mengelola pengeluaran kas, maka dibuatlah aplikasi pencatatan pengeluaran kas yang diperlukan oleh perusahaan untuk mengurangi kekurangan dalam sistem dan sekaligus untuk menjaga kekayaan perusahaan. Agar pengelolaan data dapat lebih cepat, ringkas dan untuk menjaga keakuratan data.

Berdasarkan uraian latar belakang permasalahan di atas, maka penyusun mencoba mengangkat permasalahan tersebut mengenai aplikasi akuntansi dengan judul "APLIKASI AKUNTANSI PENCATATAN PENGELUARAN KAS PADA PT. JASA TRANSPORTASI YALA GITHA TAMA CIREBON".

\section{KAJIAN PUSTAKA}

\subsection{Aplikasi}

Aplikasi menurut Hasan Abdurahman, Asep Ririh Riswaya (2014) adalah program siap pakai yang dapat digunakan untuk menjalakan perintah-perintah dari pengguna aplikasi tersebut dengan tujuan mendapatkan hasil yang lebih akurat sesuai dengan tujuan pembuatan aplikasi tersebut, aplikasi mempunyai arti yaitu pemecahan masalah yang menggunakan salah satu tekhnik pemrosesan data aplikasi yang biasanya berpacu pada sebuah komputansi yang diinginkan atau diharapkan maupun pemrosesan data yang di harapkan.

Jadi aplikasi merupakan sebuah program siap pakai untuk membantu pekerjaan yang sulit menjadi lebih sederhana, mudah dan dapat dimengerti oleh pengguna.

\subsection{Sistem Informasi Akuntansi}

Sedangkan sistem informasi akuntansi menurut Mas'ut, Abdan Masrura (2018) Sistem Informasi Akuntansi (SIA) adalah sebuah sistem informasi yang menangani segala sesuatu yang berkenaan dengan Akuntansi. Berdasarkan definisi di atas Sistem Informasi Akuntansi adalah sekumpulan sub sistem yang saling berkaitan satu sama lain yang menyediakan informasi berfungsi untuk mengelola seluruh aktivitas perusahaan yang diperlukan untuk pengambilan keputusan manajemen dan pimpinan perusahaan dan dapat memudahkan pengelolaan perusahaan.

\subsection{Pengeluaran Kas}

Sistem akuntansi pengeluaran kas menurut Mulyadi (2016:425) adalah suatu catatan yang dibuat untuk melaksanakan kegiatan pengeluaran baik dengan cek maupun dengan uang tunai yang digunakan untuk kegiatan umum perusahaan. Menurut Widya (2017) Aliran kas bebas (Free Cash Flow), kas lebih penting untuk membeli atau digunakan yang bertujuan melanjutkan operasi perusahaan. Arus kas tidak dapat dipertahankan terus menerus sehingga manajemen tidak sepenuhnya bebas menggunakan kas semaunya sendiri 


\section{METODE PENELITIAN}

\subsection{Metode}

Metode yang penulis gunakan dalam pembuatan Tugas Akhir ini adalah metode Waterfall. Metode Waterfall ini memungkinkan dapat mengontrol, meminimalisir kesalahan pengerjaan sistem. Proses pengembangan metode Waterfall ini sistematis dan berurutan dalam membangun sistem. Sistem yang dihasilkan akan berkualitas baik, dikarenakan pelaksanaannya secara bertahap sehingga tidak terfokus pada tahap tertentu. Tahapan dari metode Waterfall adalah:

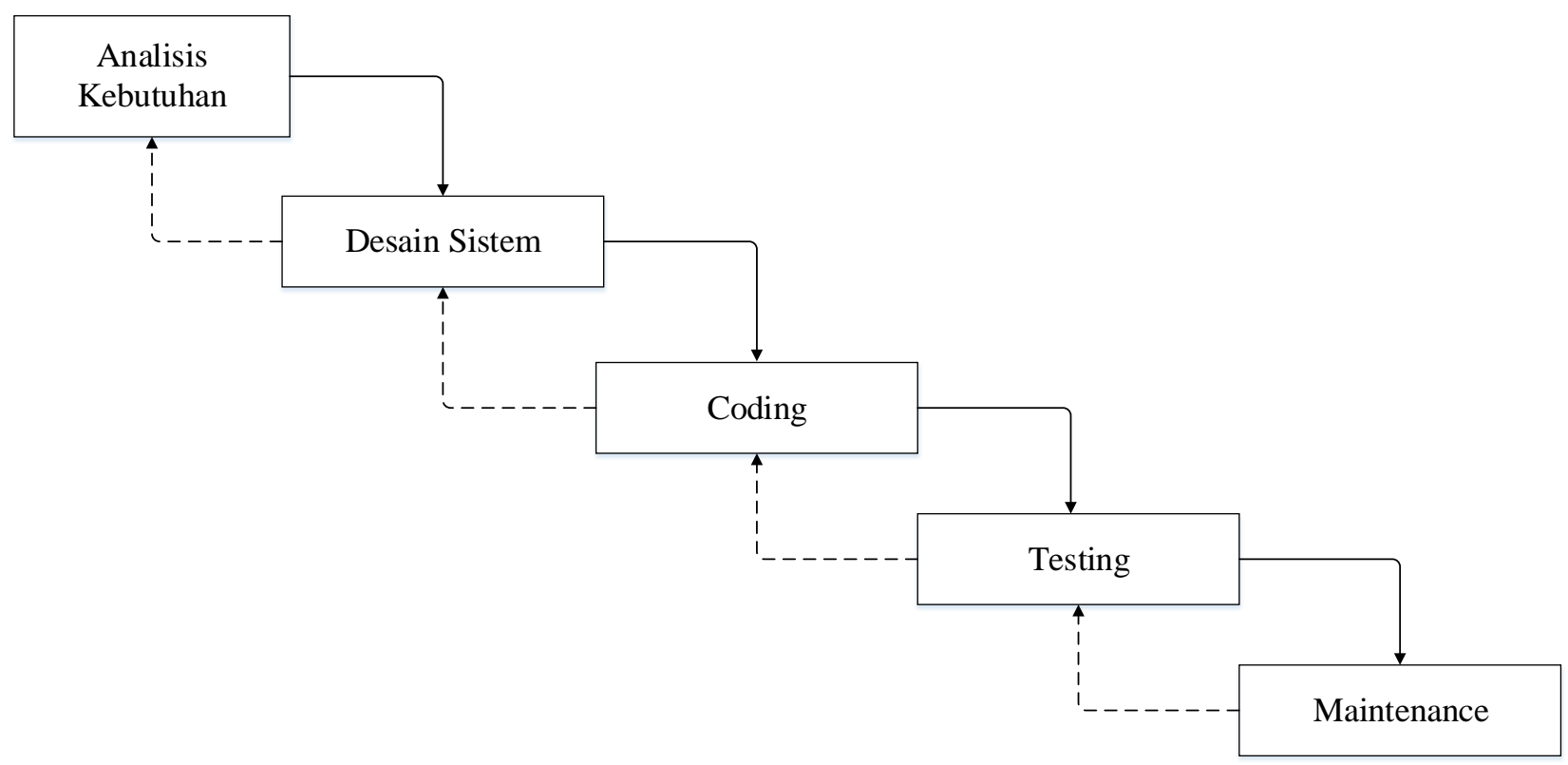

Gambar 1 Metode Waterfall

\subsection{Flowchart}

Flowchart menurut Santoso , Radna Nurmalina (2019) adalah representasi secara simbolik dari suatu algoritma atau prosedur untuk menyelesaikan suatu masalah, dengan menggunakan flowchart akan memudahkan pengguna melakukan pengecekan bagian-bagian yang terlupakan dalam analisis masalah, disamping itu flowchart juga berguna sebagai fasilitas untuk berkomunikasi antara pemrogram yang bekerja dalam tim suatu proyek. 


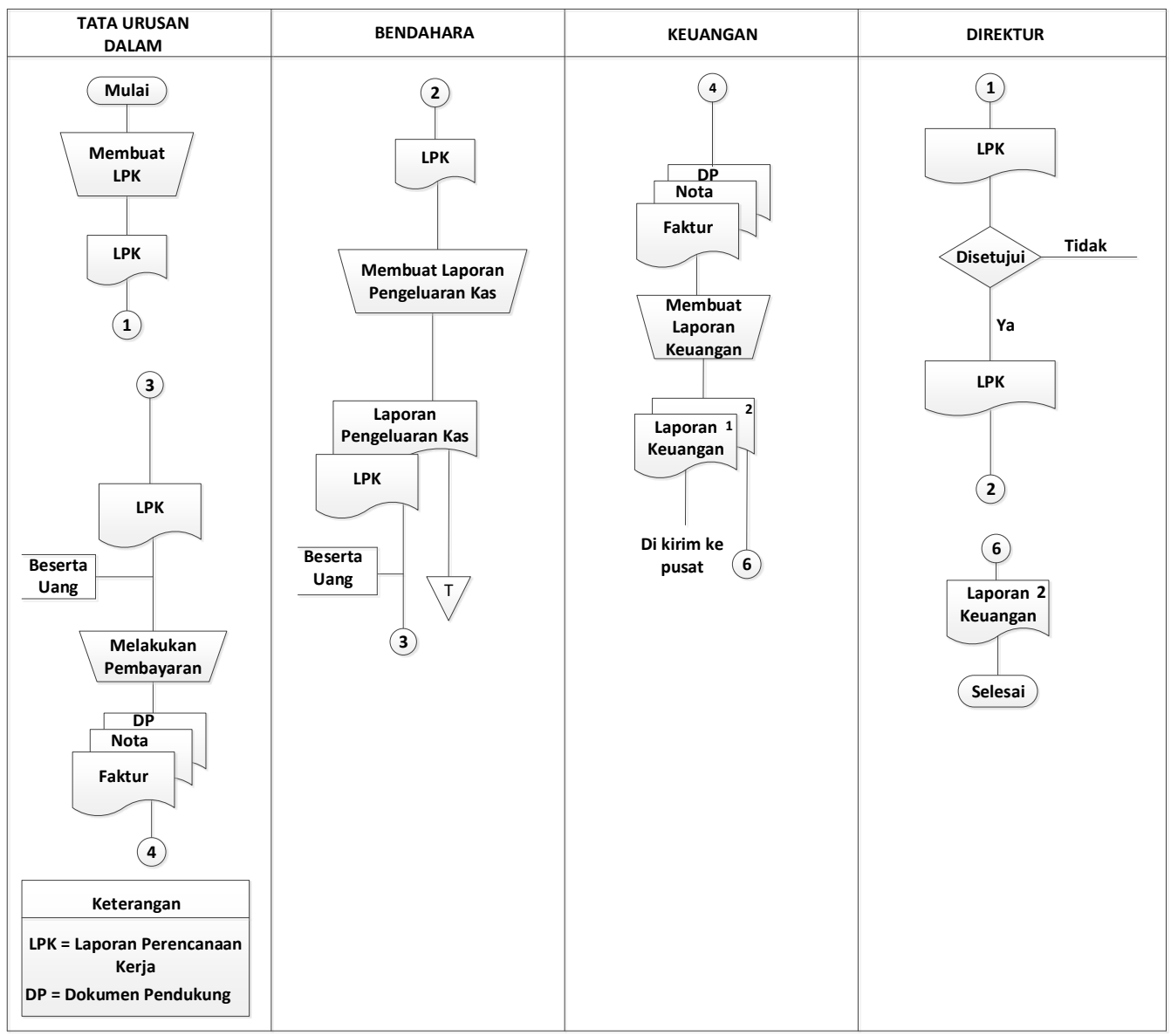

Gambar 2 Flowchart

\subsection{Flowmap}

Flowmap menurut M Haidar Bagir, Bramantiyo Eko Putro (2018) adalah campuran peta dan flowchart yang menunjukkan pergerakan benda dari satu lokasi ke lokasi lain. Seperti jumlah orang migrasi, jumlah barang yang diperdagangkan atau jumlah paket dalam jaringan. Flowmap menolong analis dan programmer untuk memecahkan masalah ke dalam segmen atau bagian yang lebih kecil dan menolong dalam menganalisis alternatif-alternatif dalam pengoperasian.

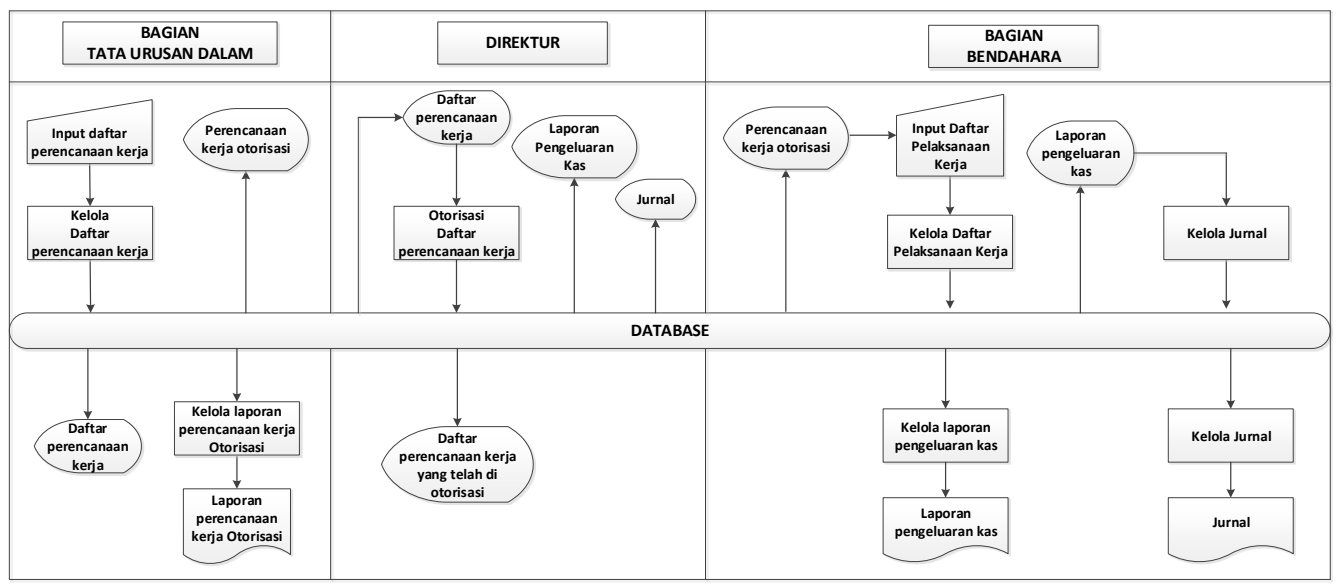

Gambar 3 Flowmap 


\subsection{Diagram Konteks}

Diagram konteks menurut Santoso , Radna Nurmalina (2019) Diagram konteks adalah diagram yang terdiri dari suatu proses dan menggambarkan ruang lingkup suatu sistem. Diagram konteks merupakan level tertinggi dari DFD yang menggambarkan seluruh input ke sistem atau output dari sistem yang memberikan gambaran tentang keseluruhan sistem

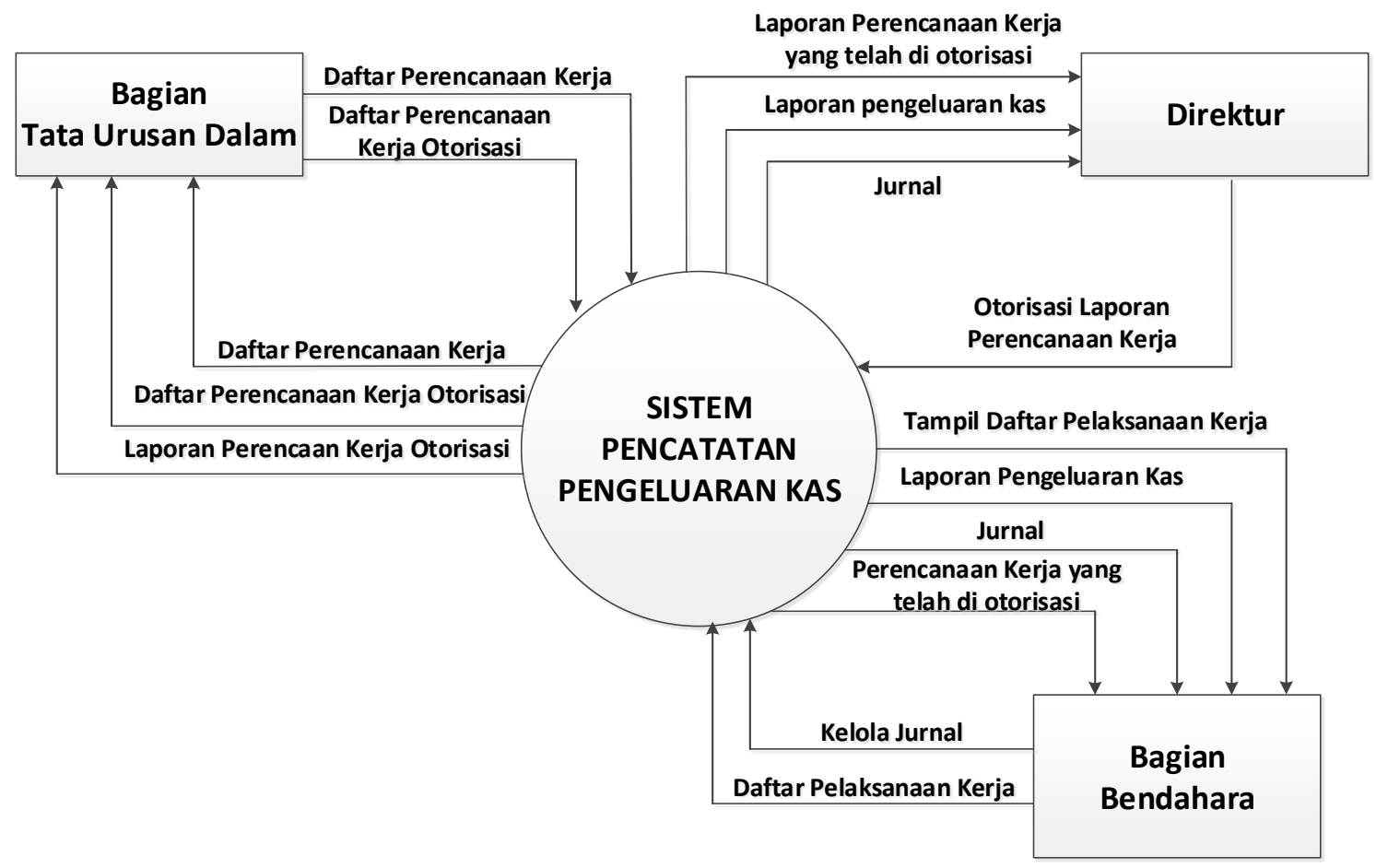

Gambar 4 Diagram Konteks

\section{PEMBAHASAN}

\subsection{Form Login}

Form Login yaitu form yang di gunakan oleh user untuk mengakses program aplikasi tersebut berdasarkan hak akses yang di dapat dari kebijakan perusahaan sebagai pemakai aplikasi.

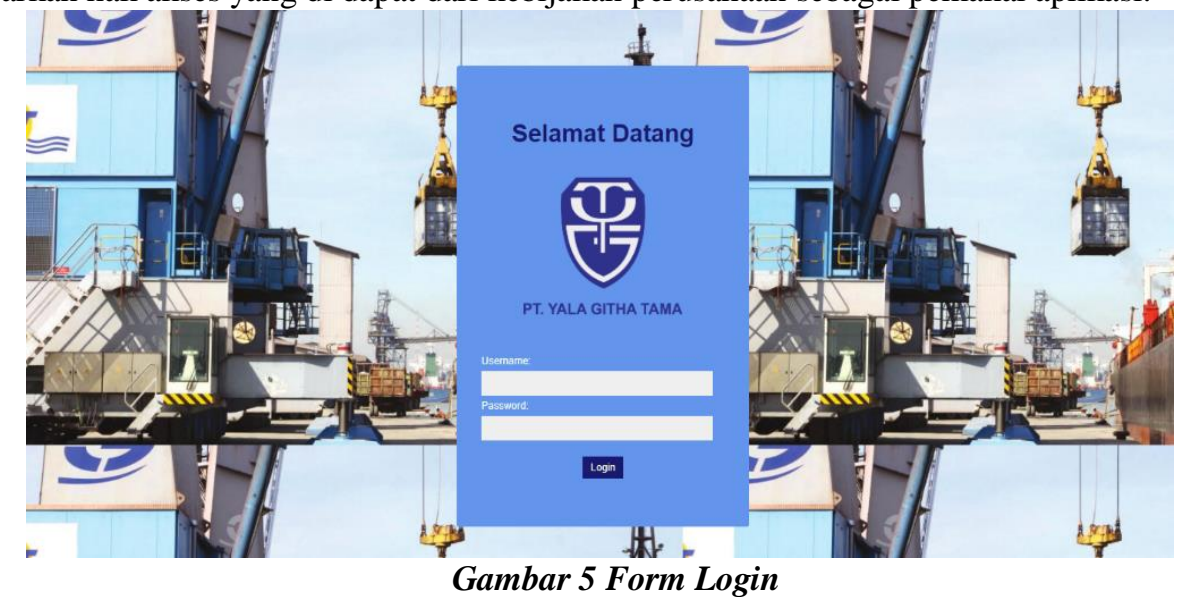

Aplikasi Akuntansi Pencatatan Pengeluaran Kas Pada PT. Jasa Transportasi Yala Githa Tama Cirebon (Widya Jati Lestari, Ilwan Syafrinal, Meirani Fajrin) 
4.2 Tampilan Bagian Tata Urusan Dalam

4.2.1 Tampilan Fowm Input Data Perencanaan Kerja

Form menu tambah data perencanaan kerja yaitu form yang di gunakan oleh bagian Tata Urusan Dalam untuk menambah data perencanaan kerja.

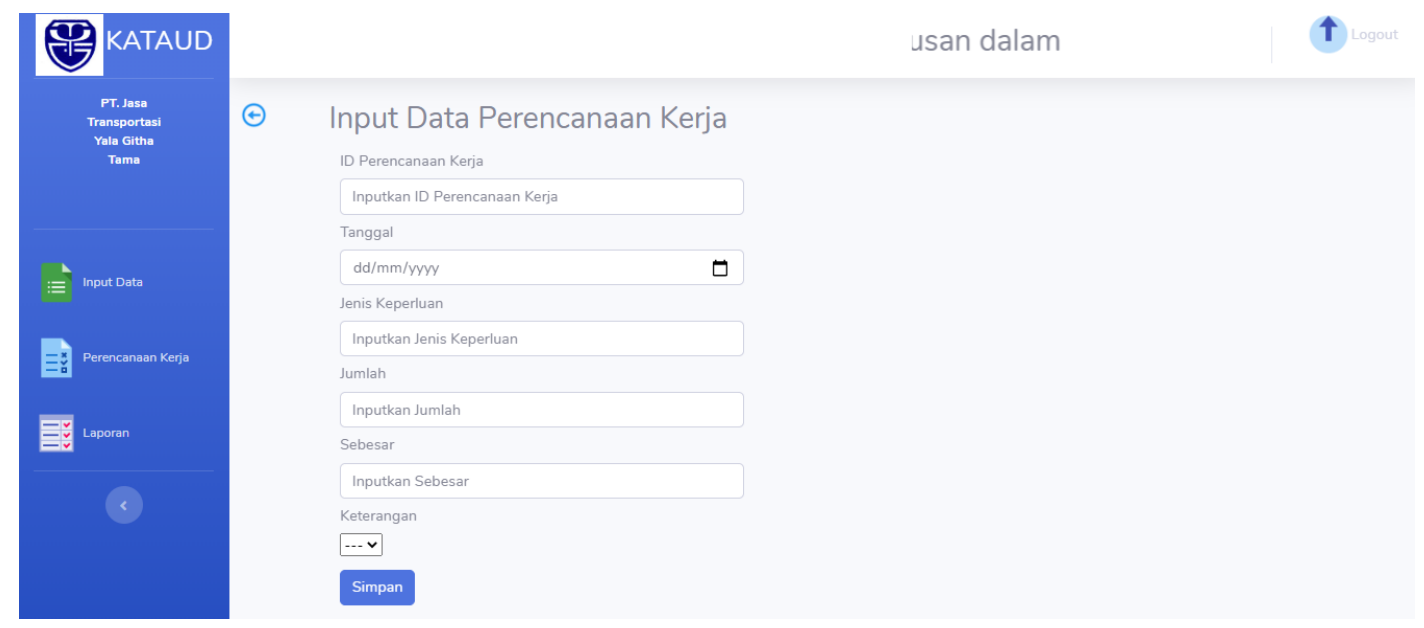

Gambar 6 Tampilan Input Perencanaan Kerja

\subsubsection{Tampilan List Perencanaan Kerja yang telah di otorisasi}

Form menu list daftar perencanaan kerja otorisasi yaitu form yang di gunakan oleh bagian Tata Urusan Dalam untuk menampilkan daftar perencanaan kerja otorisasi.

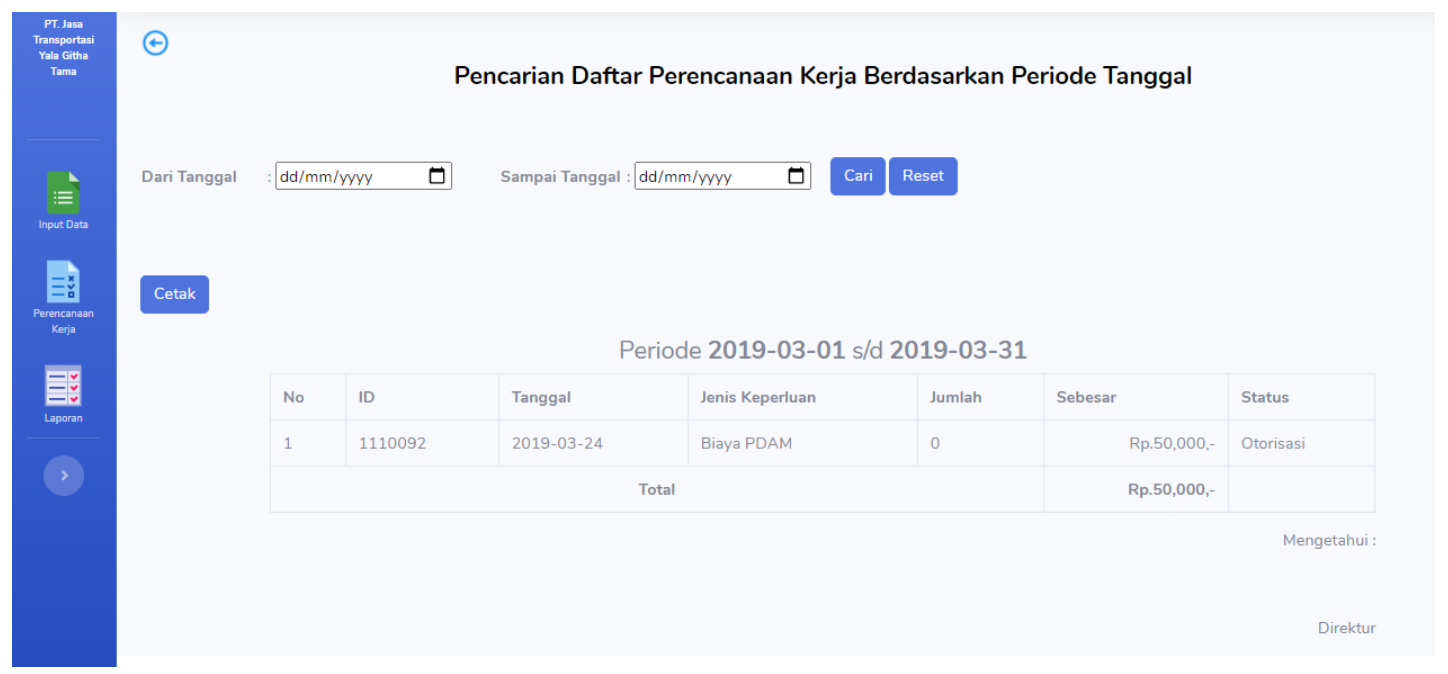

Gambar 7 Tampilan List Daftar Perencanaan Kerja Otorisasi 


\subsubsection{Tampilan Cetak Laporan perencanaan Kerja}

Form cetak daftar perencanaan kerja otorisasi yaitu form yang di gunakan oleh bagian Tata Urusan Dalam untuk mencetak daftar perencanaan kerja yang telah di otorisasi.

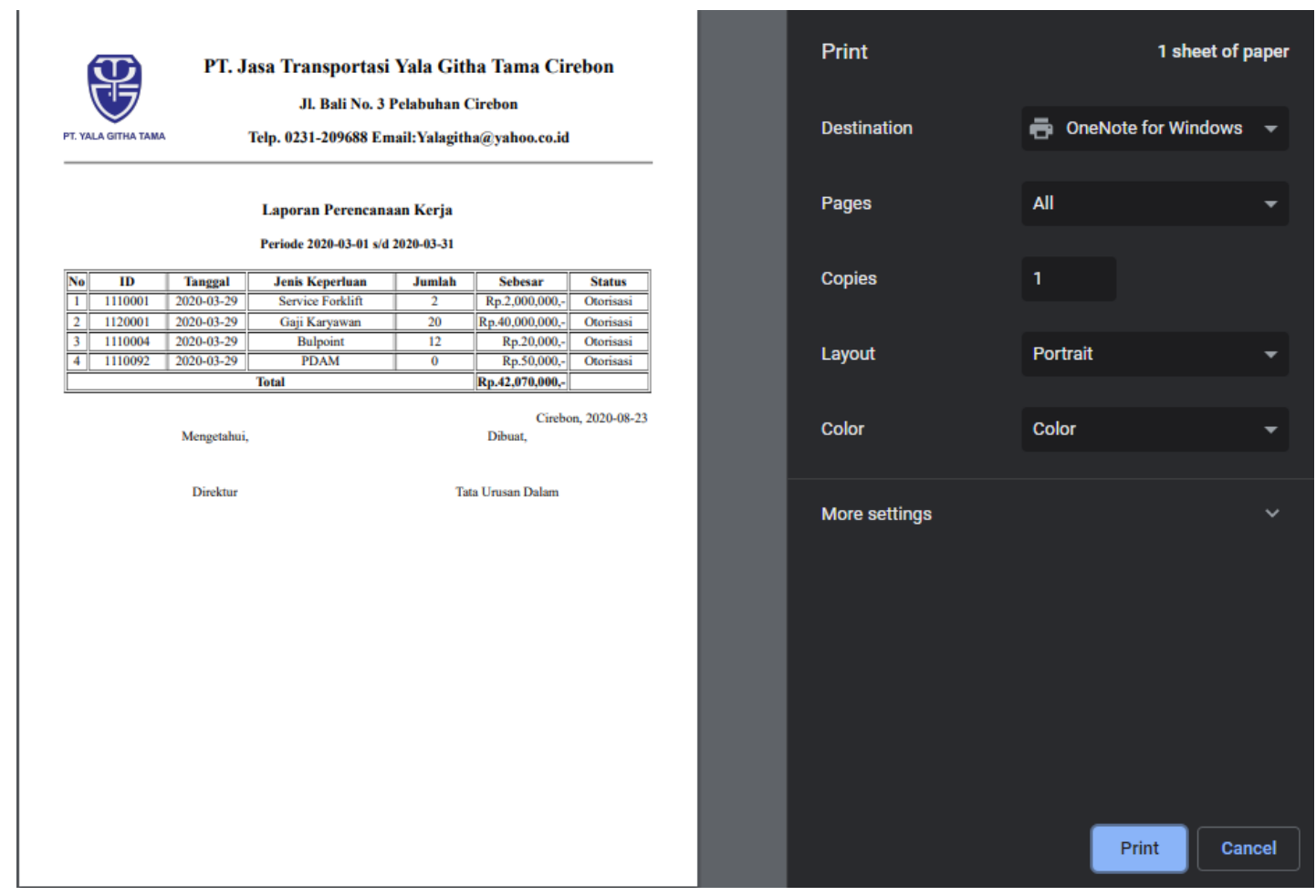

\section{Gambar 8 Cetak Laporan Perencanaan Kerja}

\subsection{Tampilan Bagian Direktur}

\subsubsection{Tampilan Menu Otorisasi}

Form menu otorisasi data perencanaan kerja yaitu form yang di gunakan oleh bagian Direktur untuk mengotorisasi data perencanaan kerja.

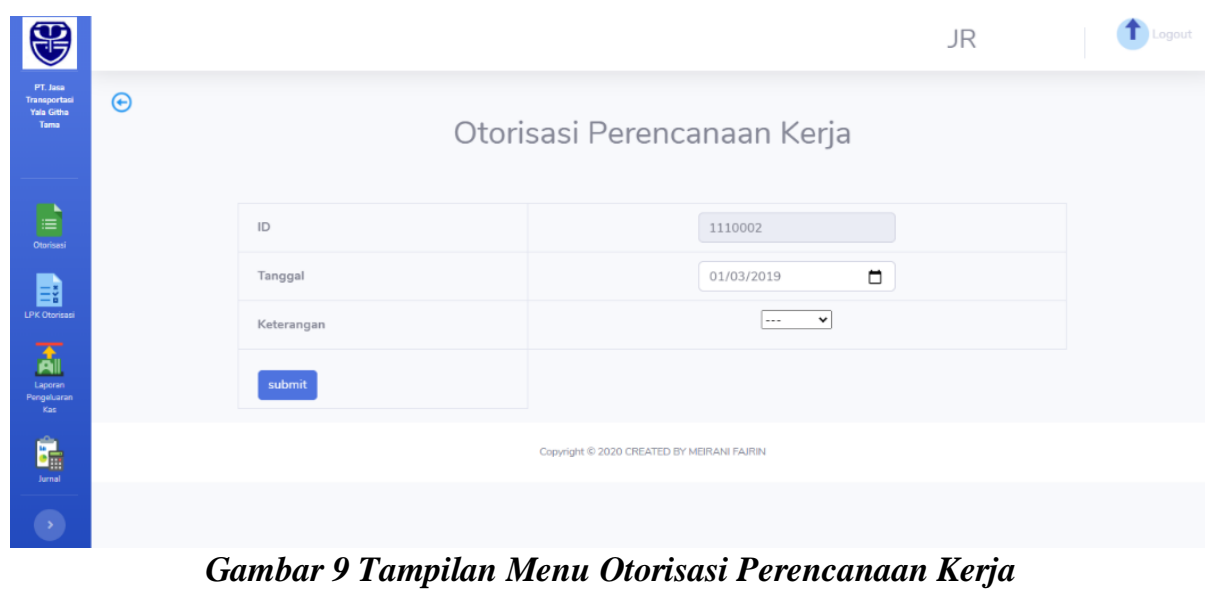

Aplikasi Akuntansi Pencatatan Pengeluaran Kas Pada PT. Jasa Transportasi Yala Githa Tama Cirebon (Widya Jati Lestari, Ilwan Syafrinal, Meirani Fajrin) 


\subsection{Tampilan Bagian Bendahara}

\subsubsection{Tampilan Menu Input Pelaksanaan Kerja}

Form menu tambah data pelaksanaan kerja yaitu form yang di gunakan oleh bagian Bendahra untuk menambah data pelaksanaan kerja.

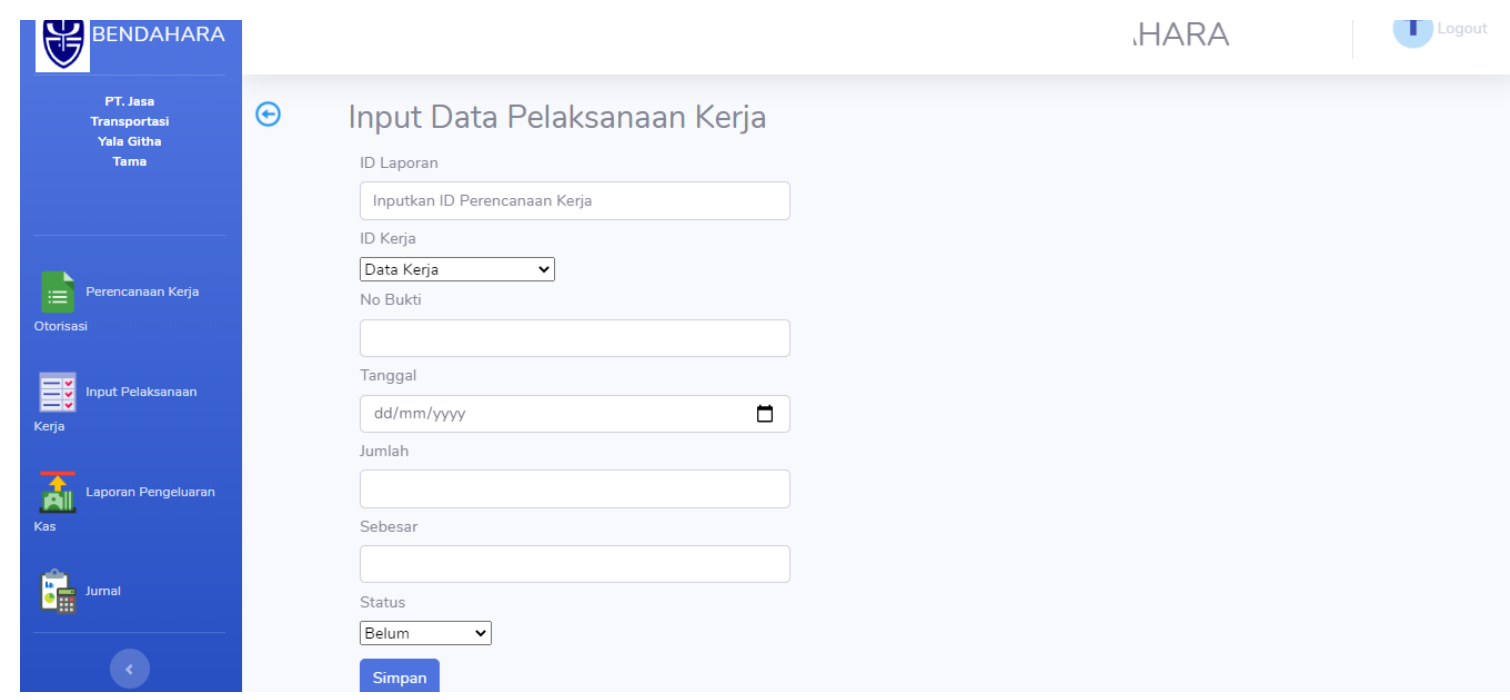

Gambar 10 Tampilan Menu Input Pelaksanaan Kerja

\subsubsection{Tampilan Menu List Pelaksanaan Kerja}

Form menu list daftar pelaksanaan kerja yaitu form yang di gunakan oleh bagian Bendahara untuk menampilkan daftar pelaksanaan kerja.

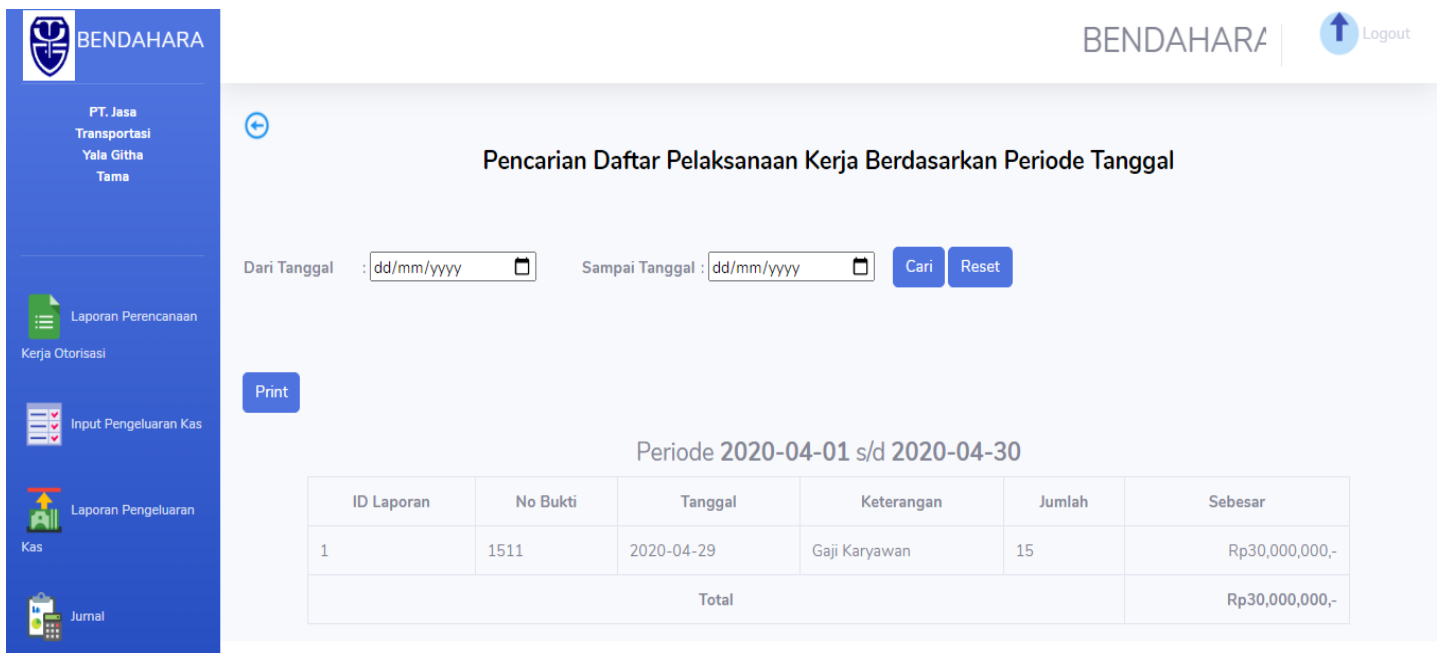

Gambar 11 Tampilan Menu List Daftar Pelaksanaan Kerja 


\subsubsection{Tampilan Cetak Laporan Pengeluaran Kas}

Form cetak laporan pengeluaran kas yaitu form yang di gunakan oleh bagian Bendahara untuk mencetak laporan pengeluaran kas.

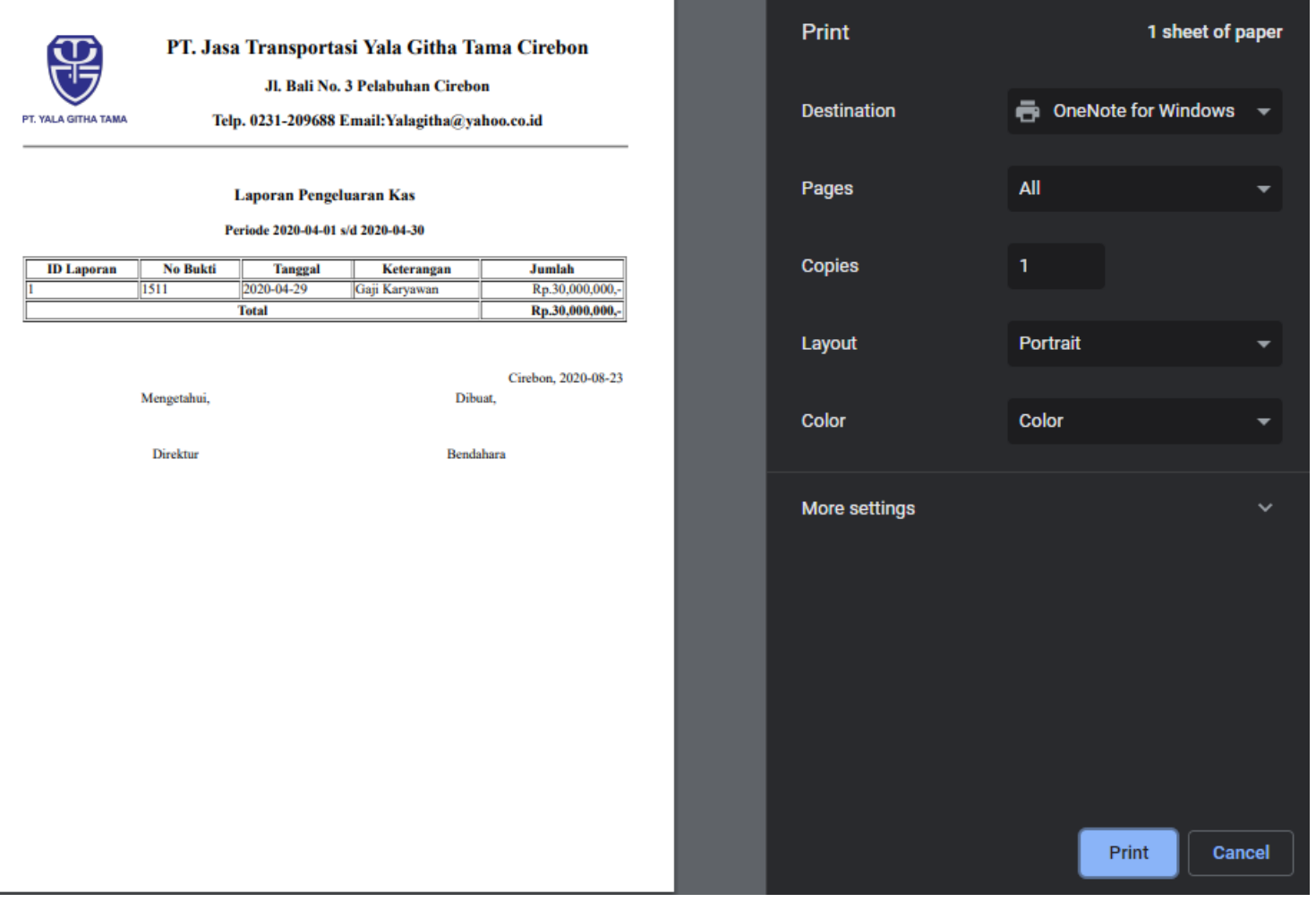

\section{Gambar 12 Tampilan Cetak Laporan Pengeluaran Kas}

\subsubsection{Tampilan Menu Jurnal}

Form menu jurnal yaitu form yang di gunakan oleh bagian Bendahara untuk menampilkan jurnal.
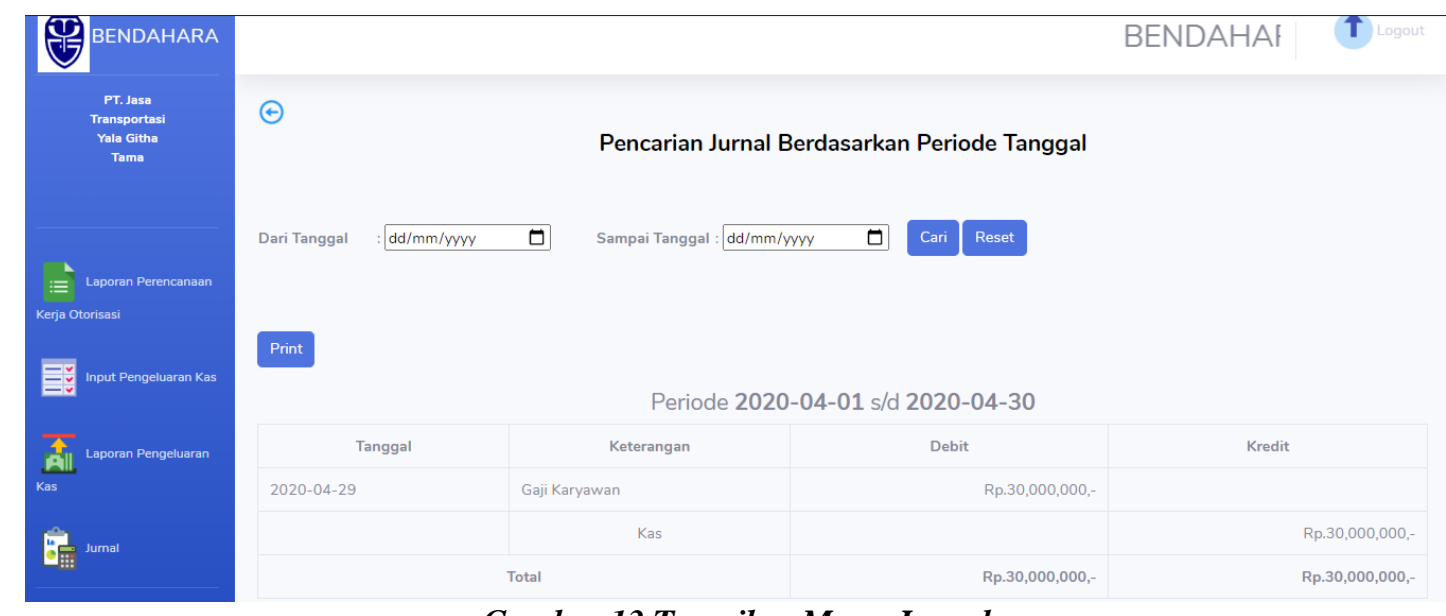

Gambar 13 Tampilan Menu Jurnal

Aplikasi Akuntansi Pencatatan Pengeluaran Kas Pada PT. Jasa Transportasi Yala Githa Tama Cirebon (Widya Jati Lestari, Ilwan Syafrinal, Meirani Fajrin) 


\subsubsection{Tampilan Cetak Jurnal}

Form menu cetak jurnal yaitu form yang di gunakan oleh bagian Bendahara untuk mencetak jurnal.

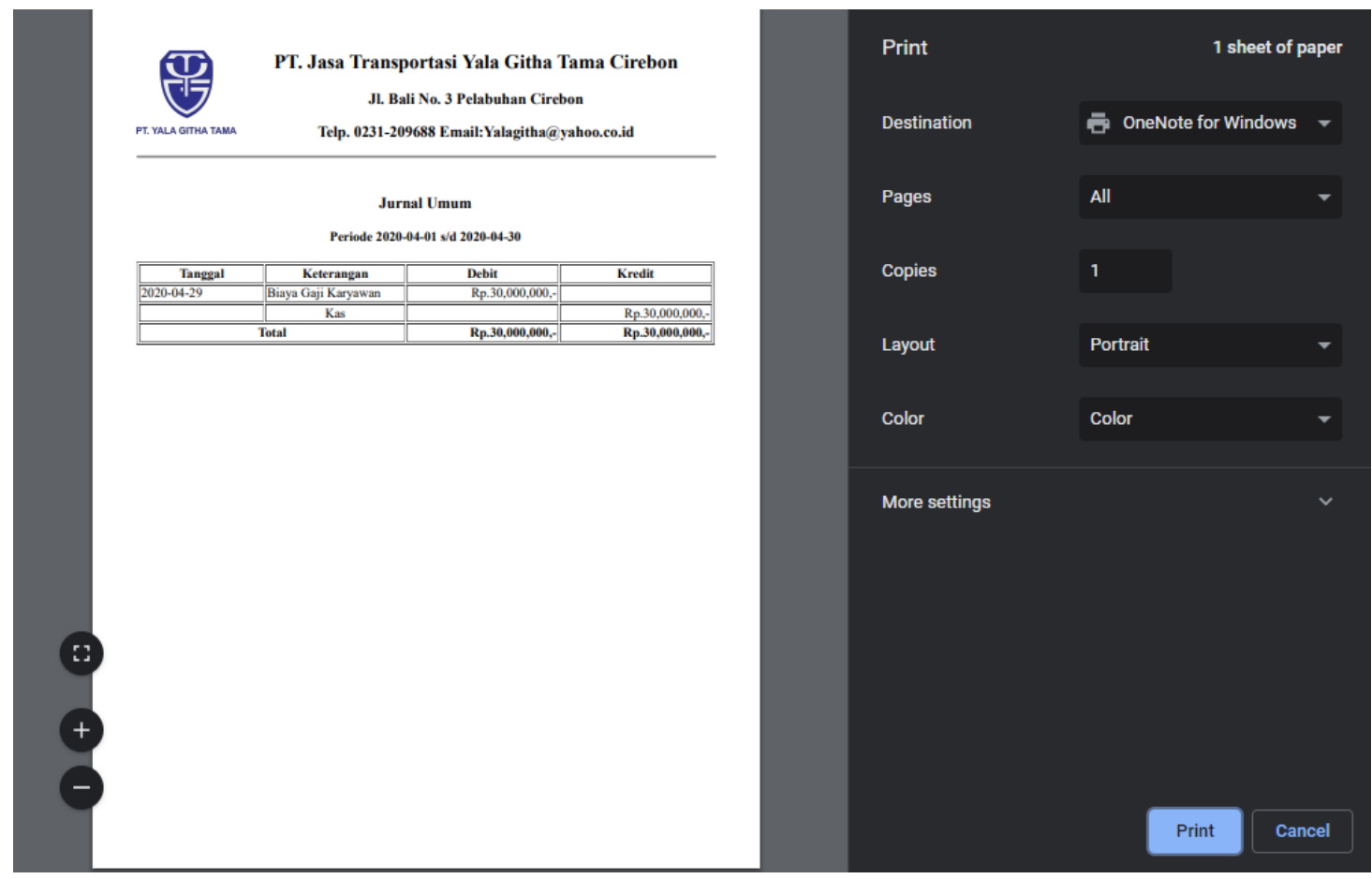

Gambar 14 Cetak Jurnal

\section{KESIMPULAN DAN SARAN}

\subsection{Kesimpulan}

Kesimpulan yang diperoleh setelah melalui pembuatan aplikasi pencatatan pengeluaran kas pada PT. Jasa Transportasi Yala Githa Tama Cirebon adalah sebagai berikut:

1. Memudahkan bagian Bendahara dalam membuat laporan pengeluaran kas dan jurnal serta memudahkan bagian Tata Urusan Dalam membuat laporan perencanaan kerja agar lebih efektif dan mempersingkat waktu pengerjaan.

2. Dengan adanya aplikasi pencatatan pengeluaran kas ini memudahkan bagian bendahara untuk mencetak laporan pengeluaran kas tanpa harus membuat secara manual.

Dengan adanya laporan perencanaan kerja ini bertujuan untuk memonitoring apa saja yang menjadi kebutuhan atau kewajiban perusahaan. Dari perencanaan kerja tersebut sebelum pencairan dana, di lakukan otorisasi terlebih dahulu.

\subsection{Saran}

Agar aplikasi pengeluaran kas pada PT. Jasa Transportasi Yala Githa Tama Cirebon berjalan dengan baik maka penulis memberikan saran untuk memperbaiki hal-hal yang masih kurang pada aplikasi yang telah dibuat seperti :

1. Sebaiknya dalam aplikasi pengeluaran kas ini dapat dikembangkan lagi agar nantinya setiap bagian dapat langsung mengajukan apa saja yang dibutuhkan melalui aplikasi ini yang kemudian nantinya akan di buat laporan perencanaan kerja oleh bagian Tata Urusan Dalam.

2. Sebaiknya dengan adanya aplikasi ini diharapkan dapat dikembangkan lagi yaitu dengan adanya penggabungan aplikasi pencatatan pengeluaran kas ini dengan aplikasi penerimaan kas yang dibuat oleh Andini Nurmayanti mahasiswa Komputerisasi Akuntansi Universitas CIC Cirebon.

3. Dengan dikembangkannya aplikasi ini menjadi di gabungkan dengan aplikasi penerimaan kas maka dapat dikembangkan lagi dengan dibuatnya laporan laba rugi. 


\section{DAFTAR PUSTAKA}

[1] Abdurahman, Hasan dan Riswaya, Asep Ririh. 2014. "Aplikasi Pinjaman Pembayaran Secara Kredit Pada Bank Yudha Bhakti”. Jurnal Computech \& Bisnis, Volume 8, Nomor 2, Halaman 62.

[2] Bagir, M Haidar dan Putro, Bramantiyo Eko. 2018. "Analisis Perancangan Sistem Informasi Pergudangan di CV. Karya Nugraha”. Jurnal Media Teknik \& Sistem Industri, Volume 2, Nomor 1, Halaman 22.

[3] Lestari, Jati Widya. 2017. "Pengaruh Struktur Kepemilikan, Struktur Modal, Free Cash Flow, Terhadap Kebijakan Inisiasi Dividen”. Jurnal Digit. Vol 7 No 2. Halaman 192-204.

[4] Mas'ut dan Masrura, Abdan. 2018. "Pengaruh Penerapan Sistem Informasi Akuntansi Terhadap Akuntabilitas Pendapatan Pajak Daerah Di Badan Pengelola Pajak Dan Retribusi Kota Medan”. Jurnal Riset Akuntansi Multiparadigma (JRAM), Volume 5, Nomor 1, Halaman 30.

[5] Santoso dan Nurmalina Radna. 2017. "Perencanaan dan Pengembangan Aplikasi Absensi Mahasiswa Menggunakan Smart Card Guna Pengembangan Kampus Cerdas (Studi Kasus Politeknik Negeri Tanah Laut)”. Jurnal Integrasi, Volume 9, Nomor 1.

\section{Texbooks:}

[1] Mulyadi. 2016. Sistem Akuntansi. Jakarta: Salemba Empat. 